\title{
Microencapsulation of a Model Oil in Wall System Consisting of Wheat Proteins Isolate (WHPI) and Lactose
}

\author{
Moshe Rosenberg ${ }^{1, *}$, Yael Rosenberg ${ }^{1}$ and Jing Zhang ${ }^{2}$ \\ 1 Department of Food Science and Technology, University of California Davis, One Shields Ave., \\ Davis, CA 95616, USA; yrosenberg@ucdavis.edu \\ 2 College of Food Science and Engineering, Northwest A\&F University, Yangling 712100, China; \\ jingzhang@nwafu.edu.cn \\ * Correspondence: mrosenberg@ucdavis.edu; Tel.: +1-530-752-4682
}

Received: 26 September 2018; Accepted: 11 October 2018; Published: 16 October 2018

Featured Application: Microencapsulating agent consisting of blends of WHPI and lactose can be utilized as an effective and highly-functional wall system for the entrapment, protection and delivery of lipids and other sensitive ingredients in food and related applications.

\begin{abstract}
Microencapsulation allows for the entrapment, protection, and delivery of sensitive and/or active desired nutrients and ingredients as well as biologically-active agents. The microencapsulating properties of wall solutions (WS) containing $2.5-10 \%(w / w)$ wheat proteins isolate (WHPI) and $17.5-10 \%(w / w)$ lactose were investigated. Core-in-wall-emulsions (CIWEs) consisting of the WS and soy oil were prepared at a wall-to-core $(\mathrm{W}: \mathrm{C})$ ratio ranging from 25:75 to 75:25 (w/w). Microcapsules were prepared by spray-drying the CIWEs. The CIWEs had a mean particle diameter smaller than $0.5 \mu \mathrm{m}$ and surface excess that ranged from 1.59 to $5.32 \mathrm{mg} / \mathrm{m}^{2}$. In all cases, microcapsules with smooth outer surfaces that exhibited only limited surface indentation were obtained. The core, in the form of protein-coated lipid droplets, was embedded throughout the wall matrices. In all but one case, core retention was higher than $83 \%$, and in $50 \%$ of the cases, it was higher than $90 \%$. Core retention was significantly influenced the composition of the WS and by W:C ratio $(p<0.05)$. Except for two cases, microcapsules exhibited very limited core extractability. The microencapsulation efficiency was $>90 \%$ and was influenced, to a certain degree, by the composition of the CIWEs. Results indicated the potential for utilizing wall systems consisting of WHPI and lactose as effective and highly functional microencapsulating agents in food and related applications.
\end{abstract}

Keywords: wheat proteins isolate; microencapsulation; spray drying; lactose; core-in-wall-emulsions; surface oil; microstructure

\section{Introduction}

Microencapsulation is a "micro-packaging" technology by which gas bubbles, liquid droplets, or solids particles, collectively referred to as "core", are embedded or entrapped in particulate matrices, referred to as "wall", thus forming structures that are referred to as "microcapsules, capsules, microspheres or micro-beads" [1,2]. Wall matrices that are utilized in food applications are designed to preserve the inherent physicochemical, biological, and/or functional properties of the encapsulated core, and, ultimately, releasing it at a desired time and conditions, at a pre-determined rate and mode [1-3]. Microencapsulation allows for controlling and modulating the interactions 
among different compounds in a given food formulation and it is aimed at protecting different constituents of food systems against deterioration or loss during processing and throughout the shelf life of the product, pending consumption [4-8]. Many different physical and chemical microencapsulation methods have been developed and allow for preparing a broad array of different microcapsules [4,9-13]. Microcapsules for food applications differ in their composition, dimensions, geometry, microstructure, physico-chemical, and textural properties, as well as in their core-release- and functional-properties $[1,3,4,6]$. Successful application of microencapsulation concepts in food systems has allowed preparing highly-functional microcapsules that are tailored to meet different, otherwise unmet objectives and challenges. Traditionally, objectives for microencapsulation in food applications included masking of off-flavors, enhancing oxidative stability of formula constituents, preventing loss of volatiles, compartmentalization of ingredients, etc. [3]. However, in recent years, the effective delivery of desired specific nutrients, sensitive- and functional- food ingredients, microorganisms, enzymes, and other biologically-active compounds has become a major objective for microencapsulation in food applications $[2,4,7,9,14-20]$. Information about the potential health-promoting properties of different natural biologically-active compounds, such as phytochemicals and constituents of different botanical extracts, calls for enhancing their consumption through foods [2]. The inherent susceptibility of many of these compounds to conditions and environments that are common in food manufacturing, delivery, and storage, requires their microencapsulation prior or during their incorporation into food products [2]. Microencapsulation has allowed meeting the latter challenge and has enabled developing and marketing a new generation of value-added food products that are referred to as "functional foods" $[2,4,7,10,21]$. The availability of generally recognized as safe (GRAS), highly functional, and affordable encapsulating agents (wall materials) is of prime importance to success in microencapsulation for food applications [2,22]. Different animal- and plant-derived proteins exhibit physico-chemical and functional properties that render them attractive encapsulating agents, or functional wall constituents, for microencapsulation in food applications. Among these desired properties are surface activity, emulsification, foaming and gelation properties, $\mathrm{pH}$-dependent zeta-potential, drying and film forming characteristics, pH-dependent solubility, etc. [23-35].

The utilization of microencapsulating agents consisting of blends of proteins and carbohydrates has been reported to allow for modulating and tailoring the manifestation of different phenomena and mechanisms that govern the encapsulation of food ingredients. A wise selection of proteins and carbohydrate for a specific application enables adjusting the physico-chemical, functional, and structural characteristics of core-in-wall-emulsions (CIWEs) and of the microcapsules that are prepared with them [30,31,36-42]. These and other reports have indicated that the protein-to-carbohydrate mass ratio, the molecular weight, functionality, and the physico-chemical properties of the proteins and carbohydrate constituents significantly influence the particles size distribution (PSD) properties of CIWEs, core retention during microencapsulation, core extractability, porosity of the wall matrices, microencapsulation efficiency (MEE), physico-chemical and microstructural features of microcapsules, as well as the rehydration and reconstitution properties of microcapsules. The microencapsulation properties of wall systems consisting of wheat proteins isolate (WHPI) and different maltodextrins and corn syrup solids have been recently reported by us [30] and the results of the study indicate that the molecular weight profile of the carbohydrate constituents affects the formation and properties of CIWEs, core retention during microencapsulation by spray drying and the MEE. In agreement with earlier reports, results of the latter study suggested the advantage of utilizing low-molecular-weight carbohydrates, especially when core extractability, MEE, and core retention are considered [30,31,43,44]. The utilization of blends consisting of different proteins and lactose as wall constituents for microencapsulation of lipids by spray drying has been reported [34,37,41,42,45-49]. These studies have indicated that the incorporation of lactose in the protein-based wall system allowed enhancing core retention and microencapsulation efficiency. It also allowed improving, in a protein type-dependent manner, the oxidative stability of encapsulated oil as well as modulating the microstructural, porosity and moisture sorption properties of the microcapsules. 
The objectives of the presented research were to: investigate the formation and properties of CIWEs consisting of model oil and blends of WHPI and lactose and then, investigate the formation and properties of spray-dried microcapsules that were prepared with these CIWEs.

\section{Materials and Methods}

\subsection{Wall and Core Materials}

Wall materials: wheat Protein isolate (WHPI, Prolite 100) containing 90\% proteins ( $w / w, \mathrm{~N} \times 6.25)$ was obtained from Archer Daniels Midland (Keokuk, IA, USA). D-lactose monohydrate was purchased from Sigma-Aldrich (St. Louis, MO, USA)

Core material: Soy oil was purchased at a local supermarket and was served as a model core material.

\subsection{Microencapsulation by Spray Drying}

Wall Solutions (WS) containing $20 \%(w / w)$ solids consisting of $2.5,5.0,7.5$, or $10.0 \%(w / w)$ WHPI and $17.5,15.0,12.5$, or $10.0 \%(w / w)$ lactose, respectively, were prepared in de-ionized water (Millipore, 18.2 M $\Omega . c m)$. Based on their solids-composition, the WS were designated 2.5/17.5, 5.0/15.0, 7.7/12.5, and 10.0/10.0, respectively. In all cases, an aqueous dispersion of WHPI was prepared at $40 \pm 1{ }^{\circ} \mathrm{C}$ and $0.02 \%$ sodium azide (Fisher Scientific, Pittsburgh, PA, USA) was added in order to prevent microbial deterioration. The WHPI dispersions were slowly stirred for $12 \mathrm{~h}$ at $25 \pm 1{ }^{\circ} \mathrm{C}$ to allow for full hydration and swelling of the protein constituents. Then, the lactose component of the WS was added and the WS was slowly stirred for $2 \mathrm{~h}$ at $25 \pm 1{ }^{\circ} \mathrm{C}$. CIWEs with a W:C mass ratio of 75:25, 50:50 and 25:75 were prepared as previously reported [30]. In short, a coarse emulsion was prepared using an Ultra-Turrax T25 homogenizer (IKA Works, Cincinnati, OH, USA) operated at 13,000 rpm for $45 \mathrm{~s}$ at $25 \pm 2{ }^{\circ} \mathrm{C}$. Then, the coarse emulsion was subjected to four successive homogenization steps (50 MPa, ambient temperature), using a model NS1001L2K-Panda high-pressure homogenizer (Niro Soavi S.p.A., Parma, Italy). The CIWEs were designated according to their WHPI and lactose content and their wall-to-core ratio (W:C). As an example, the CIWE 2.5/17.5/25:75 was prepared with WS containing $2.5 \%$ WHPI and $17.5 \%$ lactose, and it had a wall-to-core mass ratio of 25:75.

CIWEs were spray dried using an APV Anhydro Laboratory Spray Dryer (APV Anhydro A/S SØborg, Denmark). In all cases, the CIWE were atomized using the centrifugal atomizer of the dryer operated at 50,000 rpm. Drying (in the co-current configuration) was carried out at an inlet and outlet air temperature of $160 \pm 2{ }^{\circ} \mathrm{C}$, and $80 \pm 2{ }^{\circ} \mathrm{C}$, respectively. Microcapsule powders were collected, placed in hermetically closed glass jars, and kept in desiccators pending analyses.

\subsection{Analyses}

Particle size distribution: The particle size distribution (PSD) properties of the CIWE were determined using a Malvern Mastersizer MS20 (Malvern Instruments, Malvern, England). In all cases, the analysis was carried out in quadruplicates using a 2-mW He-Ne laser beam $(633 \mathrm{~nm})$ and a 45 -mm focus lens. The PSD, mean particle diameter $\left(\mathrm{d}_{3,2} \mu \mathrm{m}\right.$, volume/surface mean, also called the Sauter mean), and the specific surface area (SSA $\mathrm{m}^{2} / \mathrm{mL}$ ) were recorded.

Surface excess: The amount of protein that was adsorbed or directly engaged per unit surface area at the $\mathrm{O} / \mathrm{W}$ interface in the investigated $\operatorname{CIWE}\left(\Gamma, \mathrm{mg} / \mathrm{m}^{2}\right)$ was investigated using the procedure that had been previously reported [30]. Using a series of three successive "washing and separation" steps, the procedure allowed removing "entrapped" or loosely engaged" proteins from the O/W interface of the investigated CIWE, thus leaving only proteins that are either truly adsorbed at the $\mathrm{O} / \mathrm{W}$ interface or are tightly bound to proteins that are adsorbed at the $\mathrm{O} / \mathrm{W}$ interface. In all cases, the "washed cream" that was obtained after the third "washing and separation" step was collected and its protein and fat content was determined. 
The total protein content $(\mathrm{N} \times 6.25)$ of "washed creams" was determined, in quadruplicates, according to the Macro-Kjeldahl procedure $[50,51]$. Total oil content of separated washed creams was determined, in quadruplicates, while using a modification of the Roese-Gottlieb method [31].

Using the results of protein and fat analyses, SSA of the investigated CIWE, and $0.915 \mathrm{~g} / \mathrm{mL}$ as the density of soy oil at $25^{\circ} \mathrm{C}$, the surface excess $(\Gamma)$ of the investigated CIWEs was calculated as previously described [30], according to Equation (1).

$$
\Gamma=\frac{\mathrm{P}}{\frac{\mathrm{O}}{0.916} \times \mathrm{SSA}}
$$

where: $\Gamma$ is surface excess $\left(\mathrm{mg} / \mathrm{m}^{2}\right), P$ and $\mathrm{O}$ are protein and oil content in washed cream $(\mathrm{mg} / \mathrm{g})$, respectively, and SSA is the specific surface area of CIWE $\left(\mathrm{m}^{2} / \mathrm{mL}\right)$.

Core content: Total core (oil) content of the spray-dried (SD) microcapsules (OMC) was determined, in quadruplicates, according to a modification of the Roese-Gottlieb procedure [31,34]. Briefly, a sample $(1 \mathrm{~g})$ of SD microcapsules was reconstituted in $9 \mathrm{~mL}$ of de-ionized water and the resulted emulsion was treated with $1.25 \mathrm{~mL}$ of ammonium hydroxide. After adding $10 \mathrm{~mL}$ of ethanol, the lipids constituents of this emulsion were extracted (three successive times) with a mixture of ethyl ether and petroleum ether. The analysis was carried out in quadruplicate.

Core retention: The parameter core retention during spray drying $(\mathrm{CR})$ was defined as the ratio (expressed in \%) of core content that was included in $100 \mathrm{~g}$ of moisture-free SD microcapsules to that in $100 \mathrm{~g}$ of moisture-free CIWE solids [30,31] and it was calculated according to Equation (2).

$$
\mathrm{CR}(\%)=\frac{\mathrm{OMC}}{\mathrm{OE}} \times 100
$$

where: $\mathrm{CR}$ is core retention, $\mathrm{OMC}$ and $\mathrm{OE}$ are core (oil) content per unit mass of moisture-free SD microcapsules and CIWE solids, respectively.

Extractable oil: The parameter extractable oil $\mathrm{EO}(\mathrm{t})$ was defined as the proportion of encapsulated core that could be extracted by petroleum ether from SD microcapsules during $t$ minutes at standard extraction conditions. The extractable oil was determined as previously reported [30,31]. In short, $1 \mathrm{~g}$, of SD microcapsule was placed in a $50 \mathrm{~mL}$ Quorpak glass bottle (Fisher Scientific, Pittsburgh, PA, USA) and it was dispersed in $25 \mathrm{~mL}$ of petroleum ether (analytical grade, bp $70{ }^{\circ} \mathrm{C}$, Fisher Scientific, Pittsburgh, PA, USA)). After capping with Teflon-lined closures, the bottle was placed on a Model 360 Garver shaker (Garver Mfg., Union City, IN, USA) and the extraction was carried out for 2.5, 5.0, 15 , or $30 \mathrm{~min}$ at a gentle shaking condition (to avoid damaging the microcapsules). Following the extraction, the mixture was filtered through a $0.45 \mu \mathrm{m}, 47 \mathrm{~mm}$ diameter GN-6 filter (Gelman Science, Ann Arbor, MI, USA)), the solvent was evaporated using a water bath at $70{ }^{\circ} \mathrm{C}$, and the solvent-free extract was dried $\left(45^{\circ} \mathrm{C}, 6.7 \mathrm{KPa}\right)$. The dry extract was allowed to reach room temperature in a desiccator and its mass $(\operatorname{EOM}(\mathrm{t}))$ was then determined gravimetrically. Analysis were carried out in quadruplicate. The parameter $\mathrm{EO}(\mathrm{t})$ was calculated according to Equation (3).

$$
\mathrm{EO}(\mathrm{t})=\frac{\operatorname{EOM}(\mathrm{t})}{\mathrm{OMC}} \times 100
$$

Microencapsulation efficiency: The parameter microencapsulation efficiency, MEE, was defined as the proportion (in \%) of OMC that was not extracted by petroleum ether from the microcapsules during $5 \mathrm{~min}$.

Microencapsulation efficiency was calculated according to Equation (4).

$$
\operatorname{MEE}(\%)=\frac{\mathrm{OMC}-\mathrm{EO}(5)}{\mathrm{OMC}} \times 100
$$




\subsection{Scanning Electron Microscopy (SEM)}

The outer topography and inner structure of SD microcapsules were investigated by SEM, as previously reported [30]. Briefly, a layer of dry microcapsules was attached to a doubled sided adhesive tape (Ted Pella, Redding, CA, USA) that had been attached to a specimen holder. In order to study the inner structure, the microcapsules were fractured by moving a razor blade perpendicularly through a layer of microcapsules that were attached to the specimen holder. The specimens were coated with gold using a Polaron sputter coater (model E-50050; Bio-Rad, San Jose, CA, USA) and were analyzed using a Philips XL-FEG scanning electron microscope at $5 \mathrm{keV}$.

\subsection{Statistical Analysis}

The significance of the results was challenged at $p<0.05$ using the analysis of variance (ANOVA) test procedures that are included in the SigmaStat software (Jandel Scientific Software, San Rafael, CA, USA).

\section{Results and Discussion}

\subsection{Core-in-Wall Emulsions (CIWEs)}

Success in microencapsulation of lipids by spray drying and the stability and functionality of the dry microcapsules are significantly influenced by the formation, physico-chemical and rheological properties, stability, and functionality of the CIWE [52,53]. The formation and properties of CIWE are governed by the combined influence of the physico-chemical and surface activity of the wall constituents, the mass ratio of wall-to-core (W:C) in the CIWE, the emulsification and homogenization process conditions and the inherent properties of the core [30,53]. It has been established that, in the case of protein-stabilized CIWE, the colloidal characteristics and stability of the emulsion as well as the oxidative stability and functionality of the dry microcapsules are significantly affected by the formation, composition, structure, and rheological properties of stable protein-based films at the $\mathrm{O} / \mathrm{W}$ interfaces during the emulsification and homogenization stages of the microencapsulation process $[30,31,34,44,53,54]$. Except for a few cases, where a limited manifestation of bi-modality was evident, CIWEs exhibited a unimodal particles size distribution (Figure 1). In all cases, CIWEs were subjected to four successive homogenization steps, in the single-stage configuration, at $50 \mathrm{MPa}$. This process significantly challenged the emulsification properties of the surface-active constituents of the emulsion, the WHPI, especially when WS containing only $2.5 \%$ WHPI was used at a W:C ratio of 50:50 and 25:75. In the absence of a low-pressure second homogenization stage, every pass through the homogenization valve increased the overall interfacial surface area in the CIWE. The latter presented a significant challenge to the adsorption of proteins at the newly formed $\mathrm{O} / \mathrm{W}$ interface. The proteins had to become adsorbed at the $\mathrm{O} / \mathrm{W}$ interface at a rate and to the extent that was needed in order to stabilize this $\mathrm{O} / \mathrm{W}$ interface and to prevent coalescence or formation of homogenization aggregates [55]. Results (Figure 1) indicated that, even at the low concentration of $2.5 \%$, WHPI was effective in facilitating the formation and stabilization of CIWEs with PSD properties that are desired for microencapsulation by spray drying $[34,44,51]$. The few cases where PSD of CIWEs exhibited limited bi-modality could be attributed to the formation of homogenization clusters, especially at a high oil content and low WHPI concentration $[30,55,56]$ and, to some extent, to the adverse effect of viscosity on emulsification efficiency in some of the CIWEs that had been prepared with WSs containing 5.0 or $10.0 \%$ WHPI [55]. 


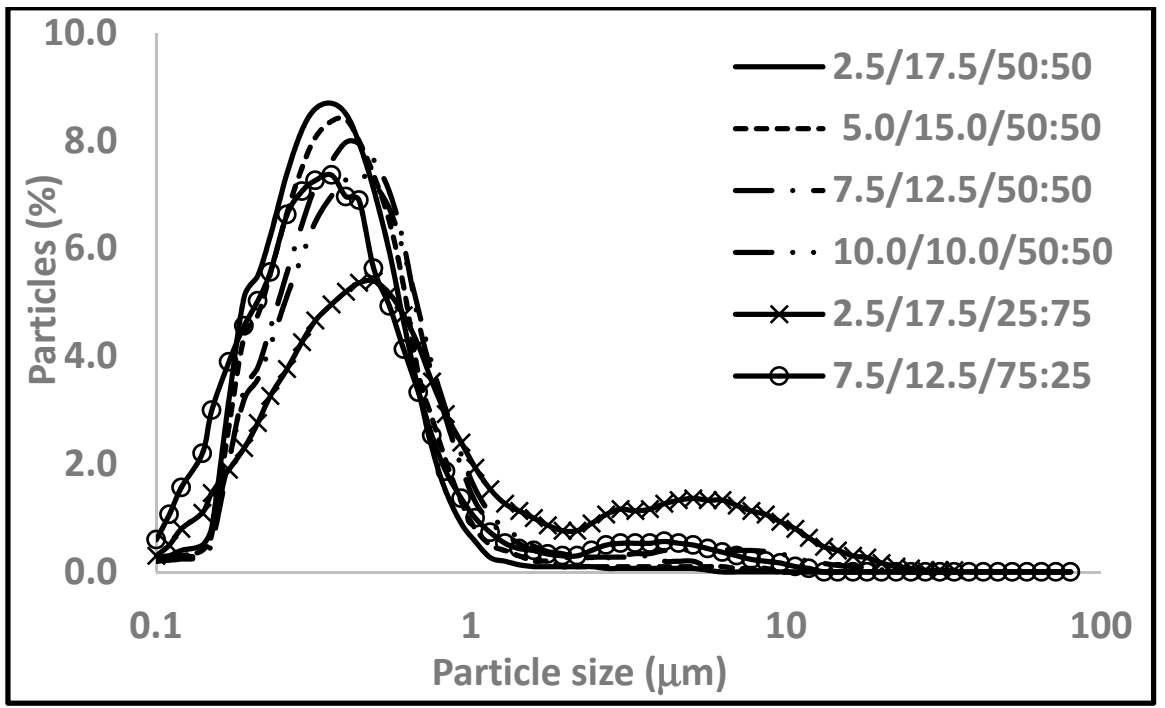

Figure 1. Representative particles size distribution (PSD) of core-in-wall-emulsions (CIWEs).

The mean particle size $\left(d_{3,2}\right)$ of the CIWEs ranged from 0.26 to $0.46 \mu \mathrm{m}$, and it was significantly $(p<0.05)$ affected by the combined influence of the W:C ratio in the CIWE and the composition of the WS that had been used for preparing the CIWE (Table 1). In all cases, for a given composition of WS, $\mathrm{d}_{3,2}$ was proportionally related to the core load in the CIWE $(p<0.05)$. Mean particle size of CIWE with a $\mathrm{W}: \mathrm{C}$ ratio of $75: 25$ was $0.02-0.15 \mu \mathrm{m}$ smaller than that in CIWE with $\mathrm{W}: \mathrm{C}$ ratio of 50:50, while that in CIWEs with a W:C ratio of 25:75 was 0.1-0.35 $\mu \mathrm{m}$ larger than that of CIWEs with a W:C ratio of 50:50 (Table 1). The extent at which $\mathrm{d}_{3,2}$ increased with core load was influenced by the solids composition of the WS (Table 1). For example, $d_{3,2}$ of CIWEs that were prepared with WS 2.5/17.5, 5.0/15.0, 7.5/12.5, and 10.0/10.0 at a W:C ratio of 75:25 was $62,69,62$, and 75\% of $d_{3,2}$ of CIWEs with W:C ratio of 25:75, respectively. At a given set of homogenization conditions and a non-limiting availability of surface active material (protein), an increase in $\mathrm{d}_{3,2}$ with lipid load can be attributed to an overall longer particle disruption time inside the homogenization valve, a longer period of time that is needed to complete the adsorption of proteins at the newly formed $\mathrm{O} / \mathrm{W}$ interface and to a very significant decrease in the particles encountering time, that is, the time that is needed for two or more partially protein-coated oil droplets to encounter each other and form a cluster $[55,56]$. Results (Table 1 ) indicated that in most cases, $\mathrm{d}_{3,2}$ of CIWE slightly, yet significantly, increased $(p<0.05)$ with the proportion of WHPI in the WS. Although not quantified in this study, CIWEs exhibited an increase in viscosity with the concentration of WHPI, especially in CIWEs with high oil content. It has to be noticed that the viscosity of CIWEs 7.5/12.5/25:75 and 10.0/10.0/25:75 was too high to allow for atomization and spray drying. The effects of the concentration of WHPI on $d_{3,2}$ could thus probably be attributed to the inverse relationships between viscosity and homogenization efficiency [55]. Results (Figure 1 and Table 1) are in agreements with earlier reports about the formation and PSD properties of CIWEs with WS consisting of proteins and carbohydrates $[30,31,43,44]$. In agreement with such earlier reports, results of this study have indicated that the utilization of a low-molecular-weight carbohydrate, lactose, allowed for preparing CIWEs with a PSD that exhibited only a very minimal manifestation of bimodality. Unlike what has been reported for CIWEs containing proteins and a low-DE-value maltodextrins [30], the inclusion of lactose in the WS did not adversely affect the formation of CIWEs with desired PSD properties. 
Table 1. The effect of wall composition and wall-to-core ratio on the mean particle sizes $\left(\mathrm{d}_{3,2}\right)$ of the investigated CIWEs.

\begin{tabular}{cccc}
\hline \multirow{2}{*}{ WHPI/Lactose (\%/\%) } & \multicolumn{3}{c}{$\mathbf{d}_{\mathbf{3}, \mathbf{2}}(\boldsymbol{\mu m})$} \\
\cline { 2 - 4 } & $\mathbf{7 5 : 2 5}$ & $\mathbf{5 0 : 5 0}$ & $\mathbf{2 5 : 7 5}$ \\
\hline $2.5 / 17.5$ & $0.260^{\mathrm{a}, \mathrm{A}}$ & $0.300^{\mathrm{b}, \mathrm{A}}$ & $0.420^{\mathrm{c}, \mathrm{A}}$ \\
$5.0 / 15.0$ & $0.300^{\mathrm{a}, \mathrm{B}}$ & $0.320^{\mathrm{b}, \mathrm{B}}$ & $0.435^{\mathrm{c}, \mathrm{A}}$ \\
$7.5 / 12.5$ & $0.290^{\mathrm{a}, \mathrm{B}}$ & $0.340^{\mathrm{b}, \mathrm{C}}$ & $0.470^{\mathrm{c}, \mathrm{B}}$ \\
$10.0 / 10.0$ & $0.345^{\mathrm{a}, \mathrm{C}}$ & $0.360^{\mathrm{a}, \mathrm{D}}$ & $0.460^{\mathrm{b}, \mathrm{B}}$ \\
\hline
\end{tabular}

Wall-to-core ratio (\%:\%, $w / w) ;{ }^{\text {a-c }}$ for a given wall system, mean values in a given row that are followed by different letters, differ significantly $(p<0.05)$; ${ }^{A-D}$ for a given column, mean values that are followed by different letters, differ significantly $(p<0.05)$.

The adsorption of proteins at the $\mathrm{O} / \mathrm{W}$ interface and the properties of the resulting interfacially-adsorbed films is of great importance to the colloidal properties, stability, and functionality of protein-stabilized CIWEs. The composition, physico-chemical-, rheological-, and structural-properties of these films also affect, to a varying degree, the oxidative stability and core-release characteristics of the microcapsules that are prepared with these CIWEs [42,54]. Results (Table 2) indicated that the surface excess $(\Gamma)$ of the CIWEs ranged from 1.597 to $5.316 \mathrm{mg} / \mathrm{m}^{2}$ and was influenced by the combined effects of the composition and PSD properties of the CIWE $(p<0.05)$. In most cases, for a given $\mathrm{W}: \mathrm{C}$ ratio, $\Gamma$ increased with the proportion of WHPI that was included in the CIWE $(p<0.05)$, however, at a $\mathrm{W}: \mathrm{C}$ ratio of 50:50 and 25:75, similar $\Gamma$ was obtained with wall systems 7.5/12.0 and 10.0/10.0 ( $p>0.05)$. In all cases, for a given wall composition, $\Gamma$ was inversely related to the core content of the CIWE $(p<0.05)$ and it thus reflected the overall increase in the interfacial area with core load. The extent to which $\Gamma$ decreased with the increase in core content was influenced by wall composition. For example, $\Gamma$ in CIWE 2.5/17.5/25:75 and 10.0/10.0/25:75 was 42 and 27\% lower than that in CIWE 2.5/17.7/75:25 and 10.0/10.0/75:25, respectively. However, $\Gamma$ in CIWEs 5.0/15.0/25:75 and 7.5/12.5/25:75 was 14 and 9\% lower than that in CIWEs 5.0/15.0/75:25 and 7.5/12.5/75:25, respectively. Overall, the results were in agreement with what has been reported for CIWEs with wall systems consisting of WHPI and maltodextrins [30]. As explained in Section 2.3, and in agreement with what has been previously reported [30], the results reflected the presence of only protein molecules that were truly engaged at the $\mathrm{O} / \mathrm{W}$ interface. The amount of protein that was adsorbed at a unit area of the $\mathrm{O} / \mathrm{W}$ interface reflected the overall results of protein adsorption at the $\mathrm{O} / \mathrm{W}$ interface during the homogenization, some post-homogenization "spreading" of such proteins at the $\mathrm{O} / \mathrm{W}$ interface, and those protein molecules from the bulk phase of the emulsion that became tightly bound, through stable protein-protein interactions, to protein molecules that were truly adsorbed at the $\mathrm{O} / \mathrm{W}$ interface $[30,55]$. Results (Table 2 ) indicated that, for a given $\mathrm{W}: \mathrm{C}$ ratio, surface excess increased with WHPI concentration in the WS $(p<0.05)$ and results of PSD analysis indicated very small among-CIWEs differences in $\mathrm{d}_{3,2}$ (Table 1 ). It can thus be suggested that the increase in $\Gamma$ with protein load in the CIWE could probably be attributed to the contribution of post-homogenization stable protein-protein interactions at the already established interfacially-adsorbed film, and, consequently, the formation of "multi-layer films" or "advanced structures" at the $\mathrm{O} / \mathrm{W}$ interface $[30,55,56]$. 
Table 2. The effect of wall composition and wall-to-core ratio on Surface Excess $(\Gamma)$ of the investigated CIWEs.

\begin{tabular}{cccc}
\hline \multirow{2}{*}{ WHPI/Lactose $(\% / \%, w / w)$} & \multicolumn{3}{c}{ Surface Excess $\left(\mathbf{m g} / \mathbf{m}^{\mathbf{2}}\right)$} \\
\cline { 2 - 4 } & $\mathbf{7 5 : 2 5 ^ { \mathbf { 1 } }}$ & $\mathbf{5 0 : 5 0}$ & $\mathbf{2 5 : 7 5}$ \\
\hline $2.5 / 17.5$ & $2.741^{\mathrm{a}, \mathrm{A}}$ & $2.402^{\mathrm{b}, \mathrm{A}}$ & $1.597^{\mathrm{c}, \mathrm{A}}$ \\
$5.0 / 15.0$ & $3.513^{\mathrm{a}, \mathrm{B}}$ & $3.32^{\mathrm{b}, \mathrm{B}}$ & $3.047^{\mathrm{c}, \mathrm{B}}$ \\
$7.5 / 12.5$ & $4.628^{\mathrm{a}, \mathrm{C}}$ & $4.468^{\mathrm{b}, \mathrm{C}}$ & $4.198^{\mathrm{c}, \mathrm{C}}$ \\
$10.0 / 10.0$ & $5.316^{\mathrm{a}, \mathrm{D}}$ & $4.453^{\mathrm{b}, \mathrm{C}}$ & $4.089^{\mathrm{c}, \mathrm{C}}$ \\
\hline
\end{tabular}

${ }^{1}$ Wall-to-core ratio $(\%: \%, w / w) ;{ }^{\text {a-c }}$ for a given wall system, mean values in a given row that are followed by different letters, differ significantly $(p<0.05)$; ${ }^{\mathrm{A}-\mathrm{D}}$ for a given column, mean values that are followed by different letters, differ significantly $(p<0.05)$.

\subsection{Microstructural Features of the Spray-Dried Microcapsules}

The structural features of spray-dried microcapsules are affected by the combined influence of the composition and physico-chemical properties of the CIWE and its constituents, by the atomization conditions and by the drying conditions [45,57-59]. CIWEs were spray-dried at the same conditions, thus allowing investigating the effects of compositional aspects on the microstructure of the microcapsules. The moisture content of the spray-dried microcapsules ranged from 0.83 to $1.58 \%$. Spherical microcapsules, ranging in diameter from about 8 to about $50 \mu \mathrm{m}$, were obtained with all of the investigated CIWEs (Figure 2). The dry microcapsules exhibited smooth outer surfaces with a limited extent of surface indentation (Figure 2A,B). Structural features of the outer topography of the investigated microcapsules were similar to those that were reported for spray-dried microcapsules prepared with blends of whey proteins and lactose [45] and superior to those reported for spray-dried microcapsules consisting of SPI and lactose [37]. A close examination of the outer surface of the microcapsules revealed the presence of round "dimples", with a diameter smaller than $0.2 \mu \mathrm{m}$, that were evenly distributed all over the outer surfaces (Figure 2D). These "dimples" have been reported to represent the "footprints" of core droplets that were swept off the outer surface of the drying droplets, immediately after the atomization stage, and prior to the solidification of the outer surface and the formation of "crust" [31,35,40,43,45,59]. In all cases, studying the inner structure of the microcapsules revealed that the core was embedded in the wall matrix in the form of protein-coated oil droplets that were evenly distributed throughout the wall matrix (Figure 2C,D). The thickness of wall matrix "layers" that separated core domains was inversely proportional to the core content in the microcapsules (Figure 2C,D). Results indicated the presence of a dense layer adsorbed at the $\mathrm{O} / \mathrm{W}$ interfaces (Figure 2C,D). As previously reported [31,35,40], this layer consists of the surface active constituents of the WS, WHPI in the present case, that have become adsorbed at the O/W interface during the homogenization process. In general, the structural features of the microcapsules were similar to the microstructural features of spray-dried microcapsules with wall systems consisting of blends of whey proteins, WHPI, or SPI and carbohydrates [30,31,35,40,44], and consisted of structural elements and features that are desired in oil-containing spray-dried microcapsules $[30,31,40,59]$. Results of the structural analysis did not reveal cracks, pores, or channels connecting core domains with the outer surfaces of the microcapsules. These results suggested that the wall matrices physically isolated the core domains from the external environment $[30,31,40,59]$. 


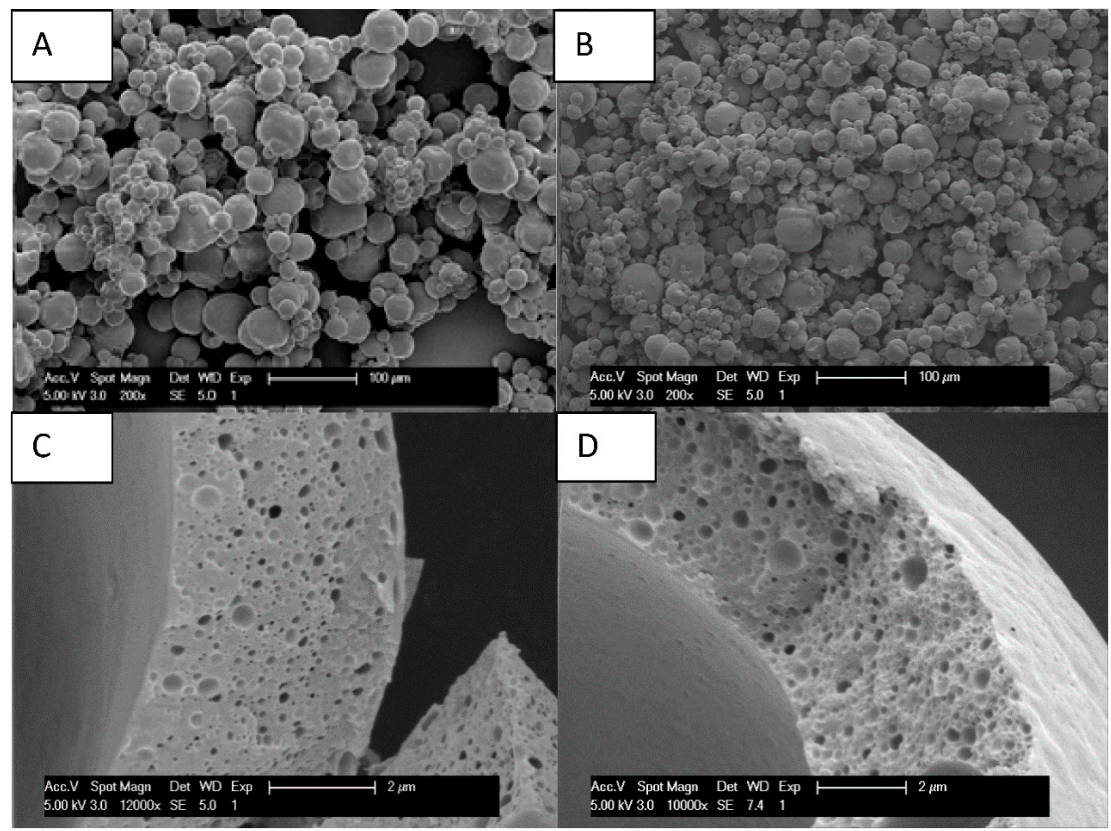

Figure 2. The typical outer topography $(\mathbf{A}, \mathbf{B})$ and inner structure $(\mathbf{C}, \mathbf{D})$ of the investigated spray-dried microcapsules. Microcapsules in (A-D) were prepared with CIWE 2.5/17.5/25:75, 5.0/15.0/50:50;2.5/17.5/25:75, and 5.0/15.0/50:50, respectively.

\subsection{Core Retention}

For a lipid-type core, the overall core losses during microencapsulation by spray drying represent losses from three sources: free core (lipids) at the outer surface of the drying capsule [60], core droplets that reside at the outer surfaces of the drying particle, immediately after the atomization stage, and core droplets that are transported from interior parts of the drying particles to the surface prior to the formation of dry crust $[30,31,34,52]$. In all but one case, core retention during spray drying was higher than $83 \%$ and $50 \%$ of the spray-dried CIWEs resulted in a core retention higher than $90 \%$ (Table 3 ). In all cases, core retention was inversely related $(p<0.05)$ to the concentration of WHPI in the wall solution (Table 3). The extent to which a given wall composition affected core retention varied among systems with different $\mathrm{W}: \mathrm{C}$ ratio (Table 3). For example, at a $\mathrm{W}: \mathrm{C}$ ratio of 75:25, core retention decreased by about $29 \%$ when the proportion of WHPI in the WS was increased from 2.5 to $10.0 \%$, while in the case of CIWE with a C:W ratio of 50:50, the decrease in core retention with WHPI concentration in the WS was by only $7.3 \%$ (Table 3). In all cases, for a given composition of WS, core retention increased $(p<0.05)$ with the core content of the CIWE (Table 3). The combined influence that the composition of the wall solution and the core load in the CIWE had on core retention could be explained by their combined effects on a multitude of variables that affected the formation and drying: the physico-chemical properties of the CIWE, the formation, drying, and properties the microcapsules during atomization and drying. Among these are the formation of droplets during atomization and their dimensions, the drying properties of the CIWE, the initial spatial distribution of core domains in the atomized droplets, and the severity of the internal mixing in the atomized droplets at early stages of the spray drying [31,52]. Results (Table 3) clearly indicated that, in all cases, core retention increased $(p<0.05)$ with the proportion of lactose in WS. The results suggested that increasing the proportion of lactose in the CIWE enhanced the drying rate of the wall matrices and thus results in a shorter constant-drying-rate phase of the drying process [30,31]. Increasing the lactose content in the CIWE thus enhanced the solidification of wall matrices and the formation of dry crust around the drying droplets spray drying [30,34]. Results suggested that, overall, the duration of the drying phase during which core droplets could be transported to- and lost from- the outer surface of the drying microcapsules was inversely related to the lactose content in the CIWE. Increasing the proportions 
of WHPI and core in the CIWEs increased the viscosity of these emulsions to the extent that CIWEs 7.5/12.5/25:75 and 10.0/10.0/25:75 could not be atomized. A higher viscosity of CIWE could have been expected to lower the extent of the internal mixing that governed the transport of core droplets to the outer surface of the drying microcapsule and thus result in a smaller core loss. However, the observed inverse relationship between core retention and WHPI content suggested that the effect of lowering the concentration of lactose in the WS on core retention was more significant and detrimental to core retention than the suggested potential effect of WHPI on the internal mixing. For a given wall composition, the increase in core retention with the core content of the CIWE could be attributed to the decrease in the relative proportion of core (out of the total core content) that resided at the outer surface of the droplets, immediately after atomization. It has been established that this proportion of the core accounts for a major part of the overall core losses $[34,43,44,52,61]$. Results of PSD analysis (Figure 1, Table 1) indicated that some small among-CIWEs differences in mean particle size were found. However, these differences were very small, and, in all cases, the $d_{3,2}$ of the atomized CIWEs was smaller than $0.44 \mu \mathrm{m}$. Potentially, the mean particle size of CIWE can affect core retention during microencapsulation by spray drying $[52,61]$. However, such an effect was reported for CIWE with a mean particle size larger than $1 \mu \mathrm{m}$ and for systems with very significant among-CIWEs differences in PSD properties [52]. It can be thus assumed that in light of the overall similar PSD properties and small $\mathrm{d}_{3,2}$ of all the CIWEs, the effect of these variables on core retention was marginal and significantly smaller than the observed effects of the composition of the CIWEs.

Overall, results indicated that maintaining the total solids content of the WS unchanged while increasing the concentration of the WHPI adversely affected core retention. Results thus highlighted the importance of including a relatively high proportion of a low molecular weight carbohydrate, such as lactose, in the CIWE as an effective means to enhance core retention during microencapsulation by spray drying.

Results of this study were in agreements with the results of some previous studies where the microencapsulating properties of wall systems consisting of proteins and lactose were investigated $[34,37,45]$.

\subsection{Core Extractability and Microencapsulation Efficiency}

Core extractability (Figure 3) was affected by the combined influence of the composition of the WS and the W:C ratio in the CIWE. The effect of extraction time on the proportion of extracted oil varied very significantly and it was dramatically influenced by the $\mathrm{W}: \mathrm{C}$ ratio in the CIWEs (Figure 3). Except for the microcapsules that had been prepared with CIWE having a W:C ratio of 25:75 (Figure 3C), the extraction time had only a very small effect on the proportion of core that was extracted from the microcapsules (Figure 3A,B). Results indicated that at a given W:C ratio, core extractability was proportionally related to the lactose content in the CIWE. Based on the results of core extractability, the investigated microcapsules could be divided into three sub-populations. The first consisted of microcapsules prepared with CIWEs at a W:C ratio 75:25 where the proportion of core that was extracted after 2.5 and $30 \mathrm{~min}$ ranged from $0.51-0.93$ to $0.74-1.1 \%$, respectively (Figure 3A). The second population consisted of microcapsules prepared with CIWEs at a W:C ratio of 50:50 where the proportion of core that was extracted after 2.5 and 30 min ranged from 1.7-3.12 to $2.26-3.45 \%$, respectively (Figure 3B). The third population (Figure 3C) consisted of microcapsules that were prepared with CIWEs at a W:C ratio of 25:75 where the proportion of core that was extracted after 2.5 and $30 \mathrm{~min}$ ranged from $9.5-15.8$ to $14.6-25.8 \%$, respectively. For microcapsules that were prepared at a $\mathrm{W}: \mathrm{C}$ ratio of 50:50 and 75:25, the very small changes in core extractability with an extraction time longer than $2.5 \mathrm{~min}$ suggested that the total proportion of extractable core (surface oil) mainly consisted of "free oil" or lipid droplets that resided at- or a small distance below- the outer surfaces of the dry microcapsules [45]. In contrast to the latter, the increase in the proportion of extractable core with extraction time that was evident in the case of microcapsules with a W:C ratio of 25:75 (Figure 3C) suggested that, in these cases, core was also extracted from domains in the interior 
parts of the dry microcapsules $[42,45,60,61]$. The relatively higher proportion of extractable core that characterized these microcapsules could be attributed to a higher proportion "surface fat" and core droplets that resided at the outer surface of these microcapsules as well as a to core that was extracted from inner domains of the dry microcapsules. The latter has been shown to reflect results of solvent diffusion, flow through capillaries, and flow empty core domains that had already been extracted [42,62]. In the case of lipids that are susceptible to oxidation, the proportion of "surface oil", especially the proportion of "free oil", significantly affects the overall oxidative stability, quality, and functionality of the microcapsules and products to which they are added [60]. The overall low proportion of core that could be extracted within 2.5 or $5 \mathrm{~min}$ from microcapsules with a W:C ratio of 75:25 and 50:50 indicated a low proportion of "surface oil". These results suggest the potential suitability of the investigated systems for effective microencapsulation of lipids.

Table 3. The effect of wall composition and wall-to-core ratio on core retention during microencapsulation.

\begin{tabular}{cccc}
\hline \multirow{2}{*}{ WHPI/Lactose $(\% / \%, w / w)$} & \multicolumn{3}{c}{ Core Retention (\%) } \\
\cline { 2 - 4 } & $\mathbf{7 5 : 2 5 ^ { \mathbf { 1 } }}$ & $\mathbf{5 0 : 5 0}$ & $\mathbf{2 5 : 7 5}$ \\
\hline $2.5 / 17.5$ & $91.15^{\mathrm{a}, \mathrm{C}}$ & $94.62^{\mathrm{b}, \mathrm{B}}$ & $97.14^{\mathrm{c}, \mathrm{B}}$ \\
$5.0 / 15.0$ & $83.72^{\mathrm{a}, \mathrm{B}}$ & $90.67^{\mathrm{b}, \mathrm{A}}$ & $93.02^{\mathrm{b}, \mathrm{A}}$ \\
$7.5 / 12.5$ & $85.40^{\mathrm{a}, \mathrm{B}}$ & $89.55^{\mathrm{b}, \mathrm{A}}$ & $\mathrm{NA}$ \\
$10.0 / 10.0$ & $70.91^{\mathrm{a}, \mathrm{A}}$ & $88.17^{\mathrm{b}, \mathrm{A}}$ & $\mathrm{NA}$ \\
\hline
\end{tabular}

${ }^{1}$ Wall-to-core ratio $(\%: \%, w / w) ;{ }^{\text {a-c }}$ for a given wall system, mean values in a given row that are followed by different letters, differ significantly $(p<0.05)$; ${ }^{\mathrm{A}-\mathrm{D}}$ for a given column, mean values that are followed by different letters, differ significantly $(p<0.05)$.

Microencapsulation efficiency (MEE), the proportion of core that was not extracted during $5 \mathrm{~min}$, ranged from 76.5 to $97.2 \%$, and was influenced, to a certain degree, by the composition of the CIWEs (Table 4). Except for two cases, the investigated microcapsules exhibited MEE $>93 \%$ and, in most cases, MEE was $>95 \%$. It has been demonstrated that, in the case of wall systems consisting of whey proteins and lactose, MEE was proportionally related to the proportion of lactose that was included in the wall system [43-45]. It has been suggested that, in those cases, the lactose formed a glassy phase during spray drying that hindered the diffusion of a non-polar solvent through the matrix and thus led to a low core extractability [44,45]. Results (Table 4) indicated that at a W:C ratio of 75:25, MEE was not influenced by the WHPI/lactose ratio in the WS and ranged from 95.8 to $96.8 \%$. At a W:C ratio of 50:50, MEE ranged from 92.2 to $95.9 \%$ and it exhibited a small, yet significant, increase with the proportion of WHPI that was included in the WS. The overall lowest MEE was exhibited by microcapsules with a W:C ratio of 25:75 that also exhibited the strongest influence of the concentration of WHPI on MEE (Table 3). At a given wall composition, MEE of microcapsules with a $\mathrm{W}: \mathrm{C}$ ratio of 75:25 was similar ( $p$ $>0.05$ ) to that of microcapsules with a W:C ratio of 50:50 (Table 4), however, MEE of microcapsules with a $\mathrm{W}: \mathrm{C}$ ratio of 25:75 was significantly lower than that at a higher $\mathrm{W}: \mathrm{C}$ ratio (Table 4 ). The overall very high level of MEE and, in most cases, the very small changes in core extractability with extraction time (Figure 3) clearly indicated that, in all cases, the lactose content of the wall matrix was effective in hindering the solvent diffusion through the wall matrices. Results indicated that, except for two cases, MEE was mainly influenced by the proportion of core that resided at- or immediately below the outer surface of the microcapsules and could thus be considered to be "surface oil" [59]. Results (Table 4 and Figure 3) suggested that the latter was inversely related to the concentration of the WHPI in the WS, thus reflecting the aforementioned effects of the WHPI content on the transport of core droplets to the surface of the drying microcapsules, prior to crust formation. The level of MEE that was accomplished in the present study with wall systems consisting of blends of WHPI and lactose was higher than what has been reported for wall systems consisting of blends of WHPI and maltodextrins or corn syrup solids [30]. 


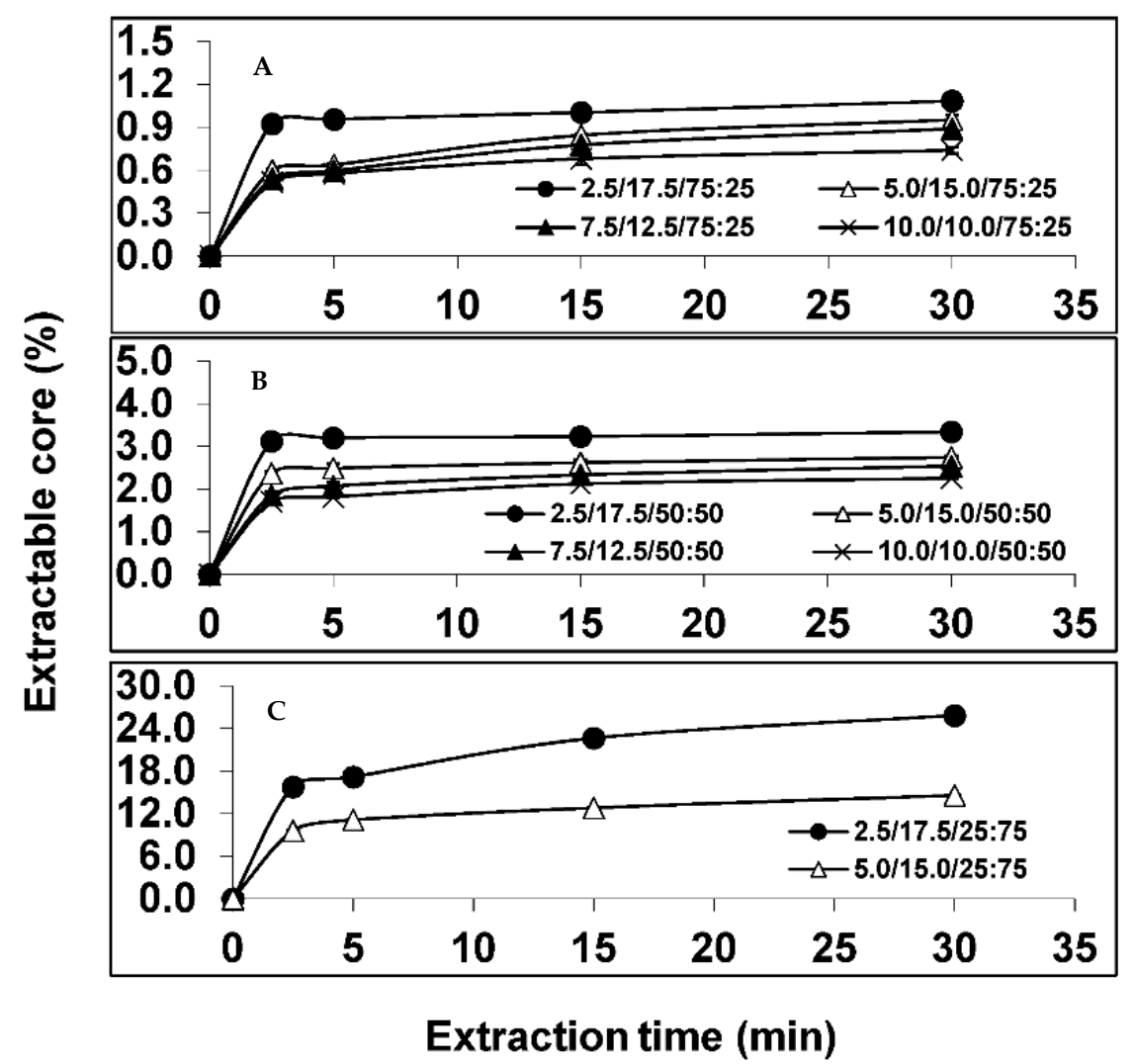

Figure 3. Effects of wall composition and extraction time on the extractable core from spray-dried microcapsules that were prepared with CIWEs at a wall-to-core ratio of 75:25 (A); 50:50; (B) and, $25: 75$ (C).

Table 4. The effect of wall composition and wall-to-core ratio on microencapsulation efficiency.

\begin{tabular}{cccc}
\hline \multirow{2}{*}{ WHPI/lactose $(\% / \%, \boldsymbol{w} / \boldsymbol{w})$} & \multicolumn{3}{c}{ Microencapsulation Efficiency (\%) } \\
\cline { 2 - 4 } & $\mathbf{7 5 : 2 5 ^ { \mathbf { 1 } }}$ & $\mathbf{5 0 : 5 0}$ & $\mathbf{2 5 : 7 5}$ \\
\hline $2.5 / 17.5$ & $95.81^{\mathrm{b}, \mathrm{A}}$ & $93.23^{\mathrm{b}, \mathrm{A}}$ & $76.45^{\mathrm{a}, \mathrm{A}}$ \\
$5.0 / 15.0$ & $96.77^{\mathrm{b}, \mathrm{A}}$ & $94.51^{\mathrm{b}, \mathrm{A}}$ & $84.10^{\mathrm{a}, \mathrm{B}}$ \\
$7.5 / 12.5$ & $97.21^{\mathrm{a}, \mathrm{A}}$ & $95.37^{\mathrm{a}, \mathrm{B}}$ & $\mathrm{NA}$ \\
$10.0 / 10.0$ & $96.75^{\mathrm{a}, \mathrm{A}}$ & $95.87^{\mathrm{a}, \mathrm{B}}$ & NA \\
\hline
\end{tabular}

${ }^{1}$ Wall-to-core ratio $(\%: \%, w / w) ;{ }^{\text {a-c }}$ for a given wall system, mean values in a given row that are followed by different letters, differ significantly $(p<0.05) ;{ }^{\mathrm{A}-\mathrm{D}}$ for a given column, mean values that are followed by different letters, differ significantly $(p<0.05)$.

\section{Conclusions}

Results of the study have indicated that blends of WHPI and lactose can be used effectively for the microencapsulation of lipids by spray drying. Results indicated that wall solutions containing as low as $2.5 \%$ WHPI provide the extent of surface activity and amount of proteins that are needed for the formation of CIWEs with desired PSD properties. The results indicated that the PSD properties and surface excess of the CIWE were influenced by the relative proportions of WHPI and lactose in the wall solutions and by the wall-to-core ratio in the CIWE. The investigated microcapsules exhibited high core retention-, and, except for two cases, high MEE- properties that were influenced by the combined influence of the solids-composition of the CIWE and by the $\mathrm{W}: \mathrm{C}$ ratio. Comparing the results of the present study to those that have been reported for wall systems consisting of blends of WHPI and maltodextrins indicated the advantage of using lactose as the carbohydrate-based constituent in the wall system. The results of the study indicated that wall systems consisting of blends of WHPI and lactose allowed for preparing microcapsules with desired properties and indicated the 
potential for utilizing WHPI as an effective and highly functional microencapsulating agent in food and related applications.

Author Contributions: M.R.: conceptualization, methodology, data processing, and writing of the paper; Y.R.: SEM and reviewing and editing the draft. J.Z. experimental work and data processing.

Funding: This research received no external funding and was funded by gift donations to author M.R.

Conflicts of Interest: The authors declare no conflict of interest.

\section{References}

1. Mishra, M. Overview of encapsulation and controlled release. In Handbook of Encapsulation and Controlled Release; CRC Press: Boca Raton, FL, USA, 2015; pp. 3-19.

2. Bleiel, S.B.; Kent, R.M.; Brodkorb, A. Encapsulation efficiency and capacity of bioactive delivery systems. In Engineering Foods for Bioactives Stability and Delivery; Roos, Y.H., Livney, Y.D., Eds.; Springer: New York, NY, USA, 2017; pp. 171-197.

3. Sobel, R.; Versic, R.; Gaonkar, A.G. Chapter 1-Introduction to microencapsulation and controlled delivery in foods. In Microencapsulation in the Food Industry; Academic Press: San Diego, CA, USA, 2014; pp. 3-12.

4. Santiago, L.G.; Castro, G.R. Novel technologies for the encapsulation of bioactive food compounds. Curr. Opin. Food Sci. 2016, 7, 78-85. [CrossRef]

5. Ray, S.; Raychaudhuri, U.; Chakraborty, R. An overview of encapsulation of active compounds used in food products by drying technology. Food Biosci. 2016, 13, 76-83. [CrossRef]

6. Zhang, C.X.; Li, X.L.; Liu, Y.N.; Zhang, F.Q. Utilization of microcapsule technology in foods. J. Nanosci. Nanotechnol. 2015, 15, 9330-9340. [CrossRef] [PubMed]

7. Vandamme, T.F.; Gbassi, G.K.; Nguyen, T.T.L.; Li, X. Chapter 41- Microencapsulating bioactives for food. In Beneficial Microbes in Fermented and Functional Foods; Ravi, V.R., Bai, J., Eds.; CRC Press: New York, NY, USA, 2015; pp. 255-271.

8. Đorđević, V.; Balanč, B.; Belščak-Cvitanović, A.; Lević, S.; Trifković, K.; Kalušević, A.; Kostić, I.; Komes, D.; Bugarski, B.; Nedović, V. Trends in encapsulation technologies for delivery of food bioactive compounds. Food Eng. Rev. 2015, 7, 452-490. [CrossRef]

9. De Souza Simões, L.; Madalena, D.A.; Pinheiro, A.C.; Teixeira, J.A.; Vicente, A.A.; Ramos, Ó.L. Micro- and nano bio-based delivery systems for food applications: In vitro behavior. Adv. Colloid Interface Sci. 2017, 243, 23-45. [CrossRef] [PubMed]

10. Li, Y.O. Nano-microencapsulation technology and applications in fortified and functional foods. Funct. Food Ingred. Nutraceuticals Process. Technol. 2016, 13, 319-371.

11. Ré, M.; Santana, M.; dAvila, M. Encapsulation technologies for modifying food performance. In Handbook of Encapsulation and Controlled Release; CRC Press: Boca Raton, FL, USA, 2015; pp. 643-684.

12. Gunasekaran, S.; Ko, S. Rationales of Nano- and Microencapsulation for Food Ingredients; John Wiley \& Sons Ltd.: Hoboken, NJ, USA, 2014; pp. 43-64.

13. Choi, M.-J.; Kwak, H.-S. Advanced Approaches of Nano- and Microencapsutation for Food Ingredients; 112 Plates; John Wiley \& Sons Ltd.: Hoboken, NJ, USA, 2014; pp. 95-116.

14. Castro-Rosas, J.; Ferreira-Grosso, C.R.; Gómez-Aldapa, C.A.; Rangel-Vargas, E.; Rodríguez-Marín, M.L.; Guzmán-Ortiz, F.A.; Falfan-Cortes, R.N. Recent advances in microencapsulation of natural sources of antimicrobial compounds used in food-A review. Food Res. Int. 2017, 102, 575-587. [CrossRef] [PubMed]

15. Turchiuli, C.; Dumoulin, E. Encapsulation of aroma. In Handbook of Encapsulation and Controlled Release; CRC Press: Boca Raton, FL, USA, 2015; pp. 833-866.

16. Martin, M.J.; Lara-Villoslada, F.; Ruiz, M.A.; Morales, M.E. Microencapsulation of bacteria: A review of different technologies and their impact on the probiotic effects. Innov. Food Sci. Emerg. Technol. 2015, 27, 15-25. [CrossRef]

17. Edwards-Lévy, F.; Munin-César, A. Encapsulation of polyphenolics. In Handbook of Encapsulation and Controlled Release; CRC Press: Boca Raton, FL, USA, 2015; pp. 741-763.

18. Desobry, S.; Debeaufort, F. Encapsulation of flavors, nutraceuticals, and antibacterials. In Handbook of Encapsulation and Controlled Release; CRC Press: Boca Raton, FL, USA, 2015; pp. 801-832.

19. Ozkan, G.; Bilek, S.E. Microencapsulation of natural food colourants. Int. J. Nutr. Food Sci. 2014, 3, 145-156. 
20. Augustin, M.A.; Hemar, Y. Nano- and micro-structured assemblies for encapsulation of food ingredients. Chem. Soc. Rev. 2009, 38, 902-912. [CrossRef] [PubMed]

21. Quek, S.Y.; Chen, Q.; Shi, J. Microencapsulation of food ingredients for functional foods. Funct. Food Ingred. Nutraceuticals Process. Technol. 2016, 13, 267-318.

22. Wani, T.A.; Shah, A.G.; Wani, S.M.; Wani, I.A.; Masoodi, F.A.; Nissar, N.; Shagoo, M.A. Suitability of different food grade materials for the encapsulation of some functional foods well reported for their advantages and susceptibility. Crit. Rev. Food Sci. 2016, 56, 2431-2454. [CrossRef] [PubMed]

23. Milad, F.; Francesco, D.; Julian, M.D. Protein-based delivery systems for the nanoencapsulation of food ingredients. Compr. Rev. Food Sci. Food Saf. 2018, 17, 920-936.

24. Sharif, H.R.; Williams, P.A.; Sharif, M.K.; Abbas, S.; Majeed, H.; Masamba, K.G.; Safdar, W.; Zhong, F. Current progress in the utilization of native and modified legume proteins as emulsifiers and encapsulants-A review. Food Hydrocoll. 2017, 76, 2-16. [CrossRef]

25. Can Karaca, A.; Low, N.H.; Nickerson, M.T. Potential use of plant proteins in the microencapsulation of lipophilic materials in foods. Trends Food Sci. Technol. 2015, 42, 5-12. [CrossRef]

26. Vasisht, N. Selection of Materials for Microencapsulation; Elsevier: Amsterdam, The Netherlands, 2014; pp. 173-180.

27. Tavares, G.M.; Croguennec, T.; Carvalho, A.F.; Bouhallab, S. Milk proteins as encapsulation devices and delivery vehicles: Applications and trends. Trends Food Sci. Technol. 2014, 37, 5-20. [CrossRef]

28. Nesterenko, A.; Alric, I.; Violleau, F.; Silvestre, F.; Durrieu, V. The effect of vegetable protein modifications on the microencapsulation process. Food Hydrocoll. 2014, 41, 95-102. [CrossRef]

29. Nesterenko, A.; Alric, I.; Silvestre, F.; Durrieu, V. Vegetable proteins in microencapsulation: A review of recent interventions and their effectiveness. Ind. Crop. Prod 2013, 42, 469-479. [CrossRef]

30. Zhang, J.; Rosenberg, Y.; Rosenberg, M. Microencapsulation properties of wall systems consisting of whpi and carbohydrates. AIMS Agric. Food 2018, 3, 66-84. [CrossRef]

31. Rosenberg, M.; Rosenberg, Y.; Frenkel, L. Microencapsulation of model oil in wall matrices consisting of spi and maltodextrins. AIMS Agric. Food 2016, 1, 33-51. [CrossRef]

32. Chen, L.; Remondetto, G.E.; Subirade, M. Food protein-based materials as nutraceutical delivery systems. Trends Food Sci. Technol. 2006, 17, 272-283. [CrossRef]

33. Liu, F.; Chen, Z.; Tang, C.-H. Microencapsulation properties of protein isolates from three selected phaseolus legumes in comparison with soy protein isolate. LWT Food Sci. Technol. 2014, 55, 74-82. [CrossRef]

34. Young, S.L.; Sarda, X.; Rosenberg, M. Microencapsulating properties of whey proteins. 1. Microencapsulation of anhydrous milk fat. J. Dairy Sci. 1993, 76, 2868-2877. [CrossRef]

35. Rosenberg, M.; Young, S.L. Whey proteins as microencapsulating agents-Microencapsulation of anhydrous milkfat-Structure evaluation. Food Struct. 1993, 12, 31-41.

36. Silva, V.M.; Vieira, G.S.; Hubinger, M.D. Influence of different combinations of wall materials and homogenisation pressure on the microencapsulation of green coffee oil by spray drying. Food Res. Int. 2014, 61, 132-143. [CrossRef]

37. Tang, C.-H.; Li, X.-R. Microencapsulation properties of soy protein isolate: Influence of preheating and/or blending with lactose. J. Food Eng. 2013, 117, 281-290. [CrossRef]

38. Karaca, A.C.; Nickerson, M.; Low, N.H. Microcapsule production employing chickpea or lentil protein isolates and maltodextrin: Physicochemical properties and oxidative protection of encapsulated flaxseed oil. Food Chem. 2013, 139, 448-457. [CrossRef] [PubMed]

39. Kartika, R.J.; Luz, S.; Ann, A.M. Stabilization of oils by microencapsulation with heated protein-glucose syrup mixtures. J. Am. Oil Chem. Soc. 2006, 83, 965-972.

40. Sheu, T.Y.; Rosenberg, M. Microstructure of microcapsules consisting of whey proteins and carbohydrates. J. Food Sci. 1998, 63, 491-494. [CrossRef]

41. Fäldt, P.; Bergenståhl, B. Spray-dried whey protein/lactose/soybean oil emulsions. 2. Redispersability, wettability and particle structure. Food Hydrocoll. 1996, 10, 431-439.

42. Fäldt, P.; Bergenståhl, B. Spray-dried whey protein/lactose/soybean oil emulsions. 1. Surface composition and particle structure. Food Hydrocoll. 1996, 10, 421-429. [CrossRef]

43. Sheu, T.Y.; Rosenberg, M. Microencapsulation by spray drying ethyl caprylate in whey protein and carbohydrate wall systems. J. Food Sci. 1995, 60, 98-103. [CrossRef] 
44. Young, S.L.; Sarda, X.; Rosenberg, M. Microencapsulating properties of whey proteins. 2. Combination of whey proteins with carbohydrates. J. Dairy Sci. 1993, 76, 2878-2885. [CrossRef]

45. Moreau, D.L.; Rosenberg, M. Microstructure and fat extractability in microcapsules based on whey proteins or mixtures of whey proteins and lactose. Food Struct. 1993, 12, 457-468.

46. Chen, W.; Wang, H.; Zhang, K.; Gao, F.; Chen, S.; Li, D. Physicochemical properties and storage stability of microencapsulated dha-rich oil with different wall materials. Appl. Biochem. Biotechnol. 2016, 179, 1129-1142. [CrossRef] [PubMed]

47. Ixtaina, V.Y.; Julio, L.M.; Wagner, J.R.; Nolasco, S.M.; Tomas, M.C. Physicochemical characterization and stability of chia oil microencapsulated with sodium caseinate and lactose by spray-drying. Powder Technol. 2015, 271, 26-34. [CrossRef]

48. Goyal, A.; Sharma, V.; Sihag, M.K.; Tomar, S.K.; Arora, S.; Sabikhi, L.; Singh, A.K. Development and physico-chemical characterization of microencapsulated flaxseed oil powder: A functional ingredient for omega-3 fortification. Powder Technol. 2015, 286, 527-537. [CrossRef]

49. Lim, H.-K.; Tan, C.-P.; Bakar, J.; Ng, S.-P. Effects of different wall materials on the physicochemical properties and oxidative stability of spray-dried microencapsulated red-fleshed pitaya (hylocereus polyrhizus) seed oil. Food Bioprocess Technol. 2012, 5, 1220-1227. [CrossRef]

50. Hooi, R.; Barbano, D.M.; Bradley, R.L.; Budde, D.; Bulthaus, M.; Chettiar, M.; Lynch, J.; Reddy, R.; Arnold, E.A. Chemical and physical methods. In Standard Methods for the Examination of Dairy Products; Arnold, E.A., Ed.; American Public Health Association: Washington, DC, USA, 2004.

51. Bakry, A.M.; Abbas, S.; Ali, B.; Majeed, H.; Abouelwafa, M.Y.; Mousa, A.; Liang, L. Microencapsulation of oils: A comprehensive review of benefits, techniques, and applications. Compr. Rev. Food Sci. Food Saf. 2016, 15, 143-182. [CrossRef]

52. Jafari, S.M.; Assadpoor, E.; He, Y.; Bhandari, B. Encapsulation efficiency of food flavours and oils during spray drying. Dry Technol. 2008, 26, 816-835. [CrossRef]

53. McClements, D.J.; Decker, E.A.; Weiss, J. Emulsion-based delivery systems for lipophilic bioactive components. J. Food Sci. 2007, 72, R109-R124. [CrossRef] [PubMed]

54. McClements, D.J. Protein-stabilized emulsions. Curr. Opin. Colloid 2004, 9, 305-313. [CrossRef]

55. Walstra, P.; Wouters, J.; Geurts, T.J. Homogenization. In Dairy Science and Technology, 2nd ed.; CRC Press: Boca Raton, FL, USA, 2006; pp. 279-296.

56. Rosenberg, M.; Lee, S.L. Microstructure of whey protein/anhydrous milkfat emulsions. Food Struct. 1993, 12, 267-274.

57. Furuta, P.W.T. Morphology and properties of spray-dried particles. In Modern Drying Technology; John Wiley \& Sons Ltd.: Hoboken, NJ, USA, 2014.

58. Lintingre, E.; Lequeux, F.; Talini, L.; Tsapis, N. Control of particle morphology in the spray drying of colloidal suspensions. Soft Matter 2016, 12, 7435-7444. [CrossRef] [PubMed]

59. Rosenberg, M.; Talmon, Y.; Kopelman, I.J. The microstructure of spray-dried microcapsules. Food Microstruct. $1988,7,15-23$.

60. Drusch, S.; Berg, S. Extractable oil in microcapsules prepared by spray-drying: Localisation, determination and impact on oxidative stability. Food Chem. 2008, 109, 17-24. [CrossRef] [PubMed]

61. Vega, C.; Roos, Y.H. Invited review: Spray-dried dairy and dairy-like-Emulsions compositional considerations. J. Dairy Sci. 2006, 89, 383-401. [CrossRef]

62. Moreau, D.L.; Rosenberg, M. Porosity of microcapsules with wall systems consisting of whey proteins and lactose measured by gas displacement pycnometry. J. Food Sci. 1999, 64, 405-409. [CrossRef]

(C) 2018 by the authors. Licensee MDPI, Basel, Switzerland. This article is an open access article distributed under the terms and conditions of the Creative Commons Attribution (CC BY) license (http://creativecommons.org/licenses/by/4.0/). 